\title{
Dr. Richard C. Nelson: Behind the Scenes
}

\author{
Doris I. Miller \\ Western University
}

\begin{abstract}
As the first PhD graduate of the Biomechanics Laboratory at the Pennsylvania State University under the leadership of Dr. Richard C. Nelson, I reflect on my early experience in sport biomechanics there and its influence on some of my subsequent, and typically unpublished, research challenges.
\end{abstract}

Keywords: RC Nelson, instrumentation, diving, running

In September 1967, I headed for Penn State having heard that Dick Nelson had started a new doctoral program in biomechanics featuring an automated film analysis system. When I got to the lab, situated in a decommissioned water tower, I discovered that the film analysis system was not exactly automated. There was no connection between the Vanguard Analyzer and the computer (Figure 1). Micheline Gagnon and I spent many hours in the dark digitizing 16-mm films. I worked the "controls" calling out runners' body segment endpoint coordinates in French while Micheline recorded them on a data sheet. We then punched the values onto computer cards and verified the numbers before submitting them as data with an analysis program at the computer center. It was not until after I graduated that the system became fully automated.

Because of my interest in competitive diving, having coached the sport for the previous 2 years, I decided to develop a 3dimensional simulation model with an accompanying computer graphics display for my doctoral dissertation. In that pre-Direct Linear Transformation era, data collection to provide validation information involved a half day of surveying the filming area to determine camera positions and targets. As the model was being developed, it took almost a week to get the results of each computer program modification. As the display was output to a large Calcomp plotter at the computer center, I would follow the pen gradually drawing successive positions of the diver in flight on the roll of 80-cm-wide paper. First, the springboard would make its appearance. But then, time after time, things would start to fall apart as the body segments rotated independently or the upper and lower body separated. Later the body stayed together, but the hips rotated in the wrong direction, and then the shoulders migrated down the trunk. Eventually, everything came together with the final product making it to the covers of the Fourth ISB Conference Proceedings and our Biomechanics of Sport book. ${ }^{1}$

While I was a faculty member at the University of Washington (1973-1984), my research continued in the area of sport biomechanics. A major project focused upon the running patterns of 32 individuals with lower-extremity amputations. ${ }^{2}$ It was carried out in cooperation with Dr Ernie Burgess of the Prosthetics Research Study and with graduate students Roger Enoka, Andy Fuglevand, Bob McCulloch, Carolyn Munro, and Gary Scheirman. Initial data collection left no doubt that many below-knee amputees could run. The majority, however, tended to lock the knee of the residual limb

Miller (dimiller@uwo.ca) is a Professor Emerita at Western University, London, ON, Canada. during stance to increase stability and/or reduce the pressure against the patellar tendon bearing prosthesis.

Before initiating the main study, we had to have a long unobstructed runway with an embedded force plate. The gymnasium in Hutchinson Hall, where our Department of Kinesiology was housed, seemed to be a logical site. Therefore, behind the scenes one Thanksgiving weekend, we hired a private contractor to cut a hole near the center of the basketball court and pour the concrete to install the mounting plate for the platform. Unfortunately, we were unable to have the plate flush with the floor without compromising structural integrity. We compensated by building plywood runways and storing them on an old mat trolley that could be rolled out before data collections. When the force platform was not in place, a piece of the original flooring masked the location of the base plate. The location was barely visible although some of the noon hour basketball players did complain that a dead spot seemed to have developed near center court!

During my tenure at the University of Western Ontario (19842000), I was able to continue competitive diving biomechanics research. In 1986, Dick phoned with one of those offers for which he was famous. How would I like to collect data at the World Diving Championships in Madrid? Under the auspices of the International Olympic Committee Medical Commission and in cooperation with Fédération Internationale de Natation, he had arranged for an international cooperative project to collect platform reaction force and video data during the competition. A force plate would be installed in the 10-m platform and Ikegami video cameras would be used to record front and side views of the takeoffs. The latter represented one of the earliest uses of video to record athletic performances for biomechanical analysis.

Once in Madrid, I was to pick up the Apple Computers shipped from the United States via Amsterdam. Initially, things were a bit tricky as Dick had not given me the airline or shipping numbers. I was also supposed to establish a "presence" around the pool so that security would get used to seeing me and know that our operation was legitimate. When the other members of our research team arrived, we set up our data collection station in the pool basement and strung wires through various vents to control the cameras and force plate. During one of the regular visits by armed security men, their bomb dog tripped over our wires almost disconnecting the setup. Each morning I had to go across the roof and down a narrow catwalk to turn on the front camera (Figure 2). At that point, I did not know how to say "don't shoot" in Spanish. In addition, we only had one small handwritten note in Spanish explaining who we were. 


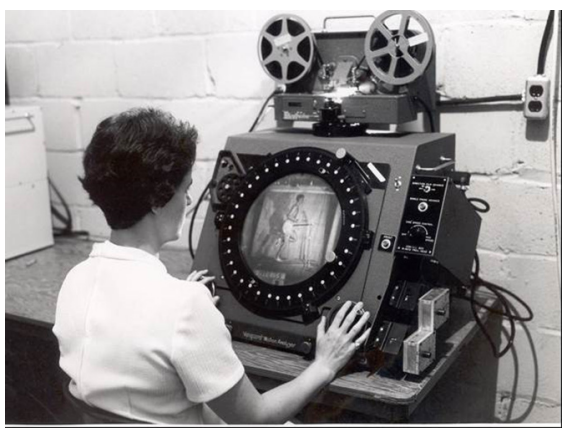

Figure 1 - The "automated" film analysis system in 1967.

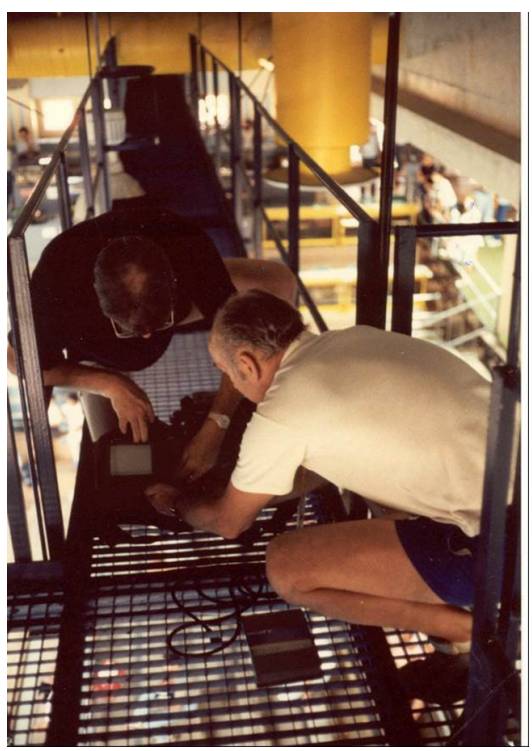

Figure 2 - Dick Nelson working on the front camera at the 1986 World Diving Championships.

The night before the competition, we checked the force plate and discovered that the vertical force changed as our human calibrator stood in various places on the plate. Apparently, it had not been isolated from its surroundings. Therefore, in the wee hours of the morning, metal and concrete cutters were brought in to deal with the problem. Dick had assured the "powers that be" that we would be invisible collecting the force and motion data and would not interfere with the competition in any way. And now we had an active construction site on the 10-m platform! Thankfully, by the time the divers arrived for their warm-up at $7 \mathrm{AM}$, the platform was isolated and operational. This meant, however, that there was no opportunity to set the platform sensitivity limits in the computer program before the competition started. Ewald Hennig had to do that "on the fly" between dives, working on a 128K Apple IIe with an accelerator card but no external memory. These platform reaction force-time histories (including those of Greg Louganis) remain the best records of this activity to date. ${ }^{3,4}$

In 1996, when I had all but forgotten the "joys" of taking part in a Dick Nelson inspired endeavor involving data collection at a major international competition, I agreed to undertake a diving research project at the Atlanta Olympics. A force plate was installed flush with the surface of the 10-m platform. Again, however, we were unable to check the system ahead of time because the pool roof collapsed effectively closing the facility until immediately before the Olympic Games. When we attempted to verify the accuracy of the center of pressure using a predetermined grid pattern, the values appeared suspect. We discovered that the graduate student assigned to the task was afraid of heights and had been down on his hands and knees on the plate at the same time he was trying to apply a point load!

Data from the Atlanta Olympics were used in a Diving Video Database analysis program written by Vladimir Klanjsek. ${ }^{5}$ Coaches could compare the performances of any 2 divers by synchronizing the video clips and adjusting their speed from single frame advance or reverse to real time. This type of qualitative feedback that many coaches had requested served as a precursor to Dartfish and other commercial video analysis programs.

In retrospect, perhaps it all started with Dick's vision of an automated 16-mm film analysis system. He believed that progress in the field had been stymied by "the lack of adequate instrumentation systems for recording and analyzing biomechanical data." 6 In the Biomechanics Laboratory at Penn State, he set about to rectify the situation. Over the years that vision has taken shape from the hand recording of film coordinates to computerized analysis of high-speed video; from graduate students writing their own computer code to perform kinetic, kinematic, and statistical calculations to commercially available programs. Through his effective international connections, Dick promoted the recording and analysis of the performances of some of the world's best athletes in high-level competition. These projects not only provided unique opportunities and insights but also entailed behind the scenes challenges. The latter, while not making it into research publications, served as the basis for stories with which Dick would regale his audiences at biomechanics conferences.

\section{Acknowledgment}

This article is based on excerpts from the author's 2006 Canadian Society of Biomechanics Career Award presentation at the University of Waterloo.

\section{References}

1. Miller DI, Nelson RC. Biomechanics of Sport. A Research Approach. Philadelphia, PA: Lea \& Febiger; 1973.

2. Miller DI. Resultant lower extremity joint moments in below-knee amputees during running stance. J Biomech. 1987;20(5):529-541. doi:10.1016/0021-9290(87)90253-3

3. Miller DI, Hennig EW, Pizzimenti MA, Jones IC, Nelson RC. Kinetic and kinematic characteristics of 10-m platform performances of elite divers: I-back takeoffs. Int J Sport Biomech. 1989;5(1):60-88. doi:10.1123/ijsb.5.1.60

4. Miller DI, Hennig EW, Pizzimenti MA, Jones IC, Nelson RC. Kinetic and kinematic characteristics of 10-m platform performances of elite divers: II—reverse takeoffs. Int J Sport Biomech. 1990;6(3):283-308. doi:10.1123/ijsb.6.3.283

5. Miller DI, Zecevic A. Olympic dives on CD—only a click away. USA Diving. 1998;6(1):5.

6. Nelson RC. Biomechanics of sport: an overview. In: Cooper JM, ed. Selected Topics on Biomechanics. Chicago, IL: Athletic Institute; 1971:31-37. 